\title{
At the Beginning of Learning Studies There Was the Maze
}

\author{
Luigi Traetta \\ Department of Humanities, University of Foggia, Foggia, Italy \\ Email: luigi.traetta@unifg.it
}

How to cite this paper: Traetta, L. (2020) At the Beginning of Learning Studies There Was the Maze. Open Journal of Medical Psychology, 9, 168-183.

https://doi.org/10.4236/ojmp.2020.94014

Received: July 12, 2020

Accepted: September 27, 2020

Published: September 30, 2020

Copyright $\odot 2020$ by author(s) and Scientific Research Publishing Inc. This work is licensed under the Creative Commons Attribution International License (CC BY 4.0).

http://creativecommons.org/licenses/by/4.0/

\begin{abstract}
A generally forgotten means of observing the developmental stages of scientific psychology is the study of maze devices. Considered in ancient times as a symbol of the process of moving in the direction of knowledge, the labyrinth, or maze, was at the centre of psychologists' attention from the end of the $19^{\text {th }}$ century. The current paper aims to reconstruct the history of the early years of maze learning, starting from the original interests of the experimenters in brain physiology or in mental evolution, and to examine how the experiments they designed continued to be important in the general theory of learning throughout the $20^{\text {th }}$ century: maze studies helped uncover general principles about learning that can be applied to many species, including humans. At the beginning of the $21^{\text {st }}$ century the question has become: what parts of the brain are used for spatial learning and memory, as shown by the Morris water maze, which is very popular in studies of behavioural neuroscience.
\end{abstract}

\section{Keywords}

Maze Test, History of Psychology, History of Learning Theories

\section{Introduction}

Francesco Segala, an architect of the $16^{\text {th }}$ century, produced a human image made up of labyrinths: the labyrinth-man symbolised the ongoing pursuit of knowledge of the inner life and the outer world. The labyrinth offered various apparent ways out, all of which had to be explored in order for it to emerge that only one was real. Four centuries later, Kerényi recalled how the labyrinth as a symbol had already been used in Mesopotamia to denote the process of moving in the direction of knowledge [1].

In the sense of a space from which it is impossible to get out without "guiding reason", the labyrinth was therefore called maze, from maes, which meant grass 
in Welsh, or field in Celtic. This definition would later denote the hedge game so loved by the aristocracy of the $16^{\text {th }}$ and $17^{\text {th }}$ centuries, and the more modern games for children involving boxes in which one or more little balls have to be guided along tortuous routes.

From this same matrix, starting from the end of the $19^{\text {th }}$ century, various psychological maze tests for evaluating animal and human learning were devised. These methodological strategies shaped by Darwinian and Spencerian evolutionism were soon taken up by other naturalists, like George Romanes, a friend of Darwin's, Douglas Spalding, and Conwy Lloyd Morgan, whose research concentrated on psychological functions such as animals' ability to learn, to memorize, to orient in the environment, to solve problems, etc. Darwin [2] himself opened the way with a series of studies on the "habits of earthworms" and their ability to represent objects. In his 1882 catalog of animal behaviour, Animal Intelligence, Romanes used the term "comparative psychology" for the first time [3] to provide empirical evidence for Darwin's hypothesis of mental continuity; Spalding investigated instincts and made observations of what would later be called "imprinting", "behavioral maturation", and "behavioral critical periods" [4] [5] [6], and Morgan, with his "canon" of parsimony, corrected what he considered excessive anthropomorphism in Romanes' work and espoused the importance of empirical investigations when reasoning with animal cognition [7].

Coincidentally with these suggestions, consciousness and mentalism were de-emphasised in favour of an orientation towards behaviour as the primary object of psychological research and towards the study of animals not essentially different from man, except in the degree of development. However, studying animal behaviour in the laboratory required techniques that were necessarily different from those applied in the study of humans: i.e., they had to be more observational and no longer based on the use of mental tests. These techniques required the ideation of new devices, such as puzzle boxes and mazes, which became "one of psychology's cornerstone methods", as they have been called [8], thanks also to the fact that the maze was "the first piece of apparatus created by psychologists themselves, and not borrowed from other disciplines such as physiology" [9]. In spite of all that, apart from a small number of studies, it has attracted little historiographic attention [10] [11].

\section{Puzzle Boxes vs. Mazes}

The question raised by Edward L. Thorndike, who in 1898 [12] became the first researcher to obtain an American doctorate in animal psychology, concerned the identification of the senses used by animals in finding a way to escape from a puzzle box. In actual fact, the device he built for experimentation was not in the shape of a labyrinth but the "situation" was similar: a maze presents more alternative paths, some of which lead into blind alleys while one leads to a goal box where there is some food or other reward. The learning process thus appears to be one of trial and error, with the correct choices reinforced by reward, and er- 
rors penalized. The term trial and error goes back to Alexander Bain, who used it in his analysis of the "constructive intellect" in the sense of a "feeling of the end to be served" and the ability to judge when that end has been satisfactorily attained [13] [14], though it was introduced into animal psychology by Lloyd Morgan [7] to describe the process by which his dog Toni learned such tricks as opening a gate by raising the latch with his muzzle, etc. Trial and error then became the main assumption underlying Thorndike's mechanistic theory.

The lectures on habit and instinct that Lloyd Morgan held in 1896 at Harvard University on the description of two forms of trial-and-error learning concerning the theory that the acquisition of skills should not have been ascribed to complex forms of associations, but to the consequences of an action, was undoubtedly what inspired Thorndike to conduct experiments with chicks, although he never mentioned his attendance at the actual lectures; he probably acknowledged his indebtedness through his professor, William James. When he moved to Columbia in 1897 to complete his M.A., he enlarged his sample to include cats and dogs. The findings were reported in his 1898 doctoral dissertation, Animal Intelligence: An Experimental Study of the Associative Processes in Animals [12], the publication of which was described "as the founding of experimental animal psychology [...]. In effect, $[\ldots]$ his work $[\ldots]$ led to the production of a convention that treats animals as abstract devices for introducing concepts that were to become common in human psychology" [15].

For his experiments Thorndike devised a number of boxes, which he called pens, with doors to be opened by turning a handle, pressing a lever, or pulling a string attached to the outside bolt: that is, using a response the various animals - mostly young cats, but also dogs, fish, chickens and monkeys - could perform as well (Figure 1) [12]. The animals responded in a number of ways, some of them ineffective: at first they clawed and scratched more or less indiscriminately but in doing so, they eventually - though unintentionally - gave the required push or pull, and so obtained their freedom or food. After some repetitions, the animal very quickly acquired the ability to do what was needed, until the trick was properly learned. The "pleasing" action was "stamped in" by success, while the indiscriminate pawing was stamped out. Thus, learning, explained with the law of effect, was due to the creation of associations between stimuli (the box)

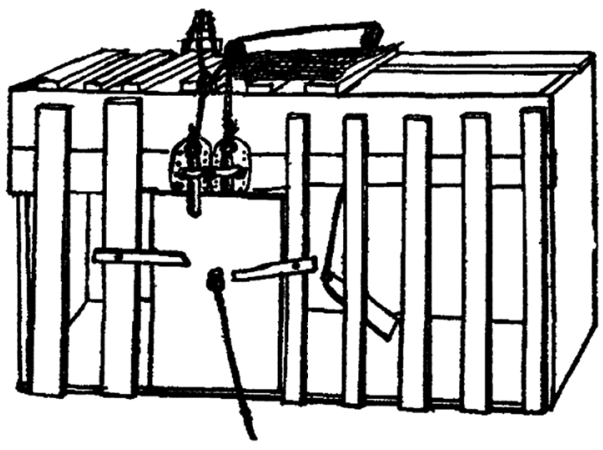

Figure 1. Thondike's puzzle box. 
and responses (e.g., stepping on the switch), and no speculation about the mind was necessary or useful. Thorndike wrote: "The possibility is that animals may have no images or memories at all, no ideas to associate. Perhaps the entire fact of association in animal is the presence of sense-impressions with which are associated, by resultant pleasure, certain impulses, and that therefore, and therefore only, a certain situation brings forth a certain act" [12]. In Thorndike's terms, the memory that formed when a hungry animal escaped from confinement (satisfier) tended to be "stamped in", whereas unsuccessful movements (annoyers) were forgotten.

The result of the numerous experiments was the production of a graph called a time curve, shaped as an $\mathrm{S}$ and showing the times taken by the animals in successive trials [12]: different species varied in how fast they learned and where their performances levelled off, with each animal producing an S curve. This seemed consistent with Romanes' idea that different species learned the same way at different speeds [16].

The animal's gradual mastery of the puzzle led Thorndike to infer that once the animal had achieved insight, after a while the trial and error would end, and the individual learning curve would show a sudden drop in time per trial. This idea remained in his subsequent essays on the issue. The first of them [17] contained no descriptions of boxes but only data already collected for his 1898 monograph, whereas his 1901 work on the mental life of monkeys presented many of the elements of later research on animals [18]. The experiments, which required the use of various puzzle boxes similar to the devices made for his doctoral thesis, concerned monkeys' activities such as distinguishing between two signals, opening complex boxes to obtain food, etc. Once again learning curves emerged [19].

Thorndike's experiments attracted considerable attention: psychologists were becoming increasingly confident that their experiments could also provide evidence about animal thinking and other cognitive processes. Nevertheless, there were various re-interpretations of Thorndike's conclusions, such as Hobhouse's observation that trial-and-error behaviour was inevitable given that the puzzle box — as had already been observed in 1912 [20] — was a blind situation for an animal, which could not inspect it at the outset, so it was necessary to change the stimulus [21], and Adams' view that trial-and-error behaviour in cats consisted of manipulatory responses to various objects and not of miscellaneous movements unrelated to the environments [22]. Bitterman would explain the importance of Thorndike's work thus: it "was objective: it minimized the influence of the observer [...]. It was quantitative: the course of learning could be measured accurately $[\ldots]$. It was reproducible: the work of one investigator could be repeated and verified by others. It was flexible: the responses required could be varied in kind and complexity. It was natural: [...] the problems presented [...] were not too remote from the animal's ordinary course of life [...]. It was convenient: a large enough sample of animals could be studied to provide a repre- 
sentative picture of each of a variety of species" [23].

For his part, Hobhouse, in Mind in Evolution, provided detailed descriptions of the various problems that he presented to cats, dogs, a monkey, elephants and a chimpanzee to solve and thus obtain food. During the experiments, conducted with different types of mechanisms in boxes (string to be pulled, string on railngs, levers, pull-bolts, push-back bolts, catches, loops, spikes, jugs or tumblers to be overturned, covers, drawers, doors to be pushed open, weights) (Figures 2-4) he noticed a sudden improvement in the learning curve, which he ascribed to the animal's ability to employ perceptual relations in problem solution. The difficulty, he often found, was to get the animal to attend to the important object. He

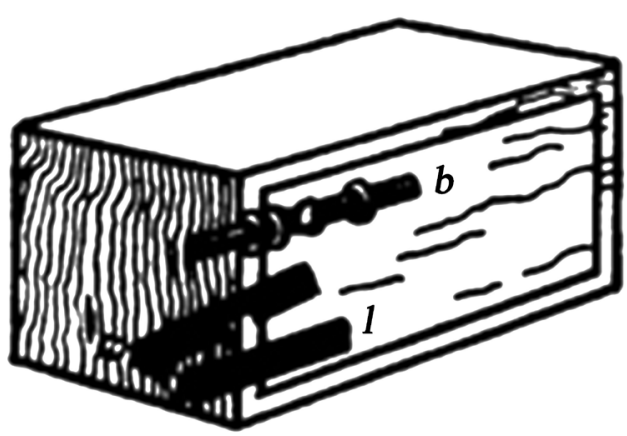

Figure 2. Hobhouse's boxes [20]. $b$, bolt, drawn; $c$, catch, raised; 1 , lever.

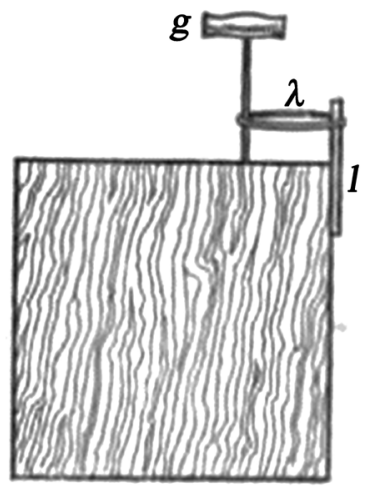

Figure 3. Hobhouse's boxes [20]. Box arranged with Loop: 1 , lever; $\lambda$, loop; $g$, gimlet.

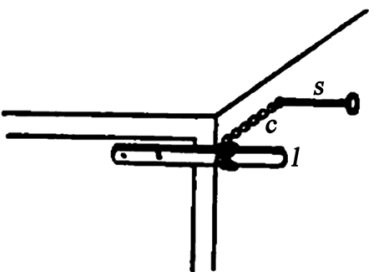

Figure 4. Hobhouse's boxes. Box arranged with Spike [20]. l, lever; $c$, chain; $s$, spike. 
called these discontinuities "practical judgment" [20], a shift away from the interpretation of learning as forms of association, because "it is a strange coincidence that the right associations are chosen. [...] In short, we find signs on the one hand of the application of ideas, on the other of selection. Both of these features indicate a higher stage than that of sheer association" [20]. Practical judgment enabled purposive action in the strict sense, that is, action in which an impulse dealt with the varying circumstances in the manner best suited to give it satisfaction. Therefore, it was distinguished from association because it was not dominated by mental habit but could select the most appropriate way for its purposes.

In 1900 and 1901 Small published his experimental research on mazes as a part of a series carried out in the Clark laboratory in the previous academic year to study the character of the associative processes of the rat. This type of experiment-Small pointed out - had already been conducted by Thorndike in Columbia laboratory and his colleague, Linus W. Kline, in the Clark laboratory itself. Small used white rats that existed only in captivity for comparative psychology laboratory studies seeking to provide a description of the psychic life of special animal forms [24]. As for the word "association", he clarified its difference from the Wundtian definition, according to which association consisted of ideational connections lacking in the characteristics of the activity of logical thought. According to Small, the term, although meaning "connections", should be interpreted in a wider sense, covering all possible connections of mental elements as indicated by animals' activities, i.e., their intelligence as conditioned by their dominant instincts, structural and functional traits, affective life, etc.. In fact, he observed six groups of rats, paying attention to the manner in which contiguous associations originated and were integrated, the persistence of such processes, the factors entering into them, recognition and discernment, imitation, and individual differences [24]. He also tested blind rats and found that their performance was similar to sighted animals. This outcome led him to infer that neither sight nor smell were important for learning, but most probably touch and kinesthesis were the keys to a rat's ability to run through a maze.

For the experimental tests, the maze was constructed following the suggestions of Clark's laboratory director, Edmund C. Sanford-as Kline recalled in a note to Miles [25] — during a conversation he had with Kline in the spring of 1898 about the "home-finding" capacities of the rat and its burrowing and digging. The device reproduced the Hampton Court maze, as depicted in the diagram of the labyrinth in the Encyclopaedia Britannica. The name "Hampton Court" derived from a labyrinth which William III had built in 1690 in the gardens of the castle of Hampton Court to a design by the gardeners George London and Henry Wise.

Small's device [26], the shape of which was designed to simulate, as far as possible, the rat's normal underground tunnelling environment [25], measured $6 \mathrm{ft}$ $\times 8 \mathrm{ft}$ and was adjusted to a rectangular pattern (Figure 5) [27]. It was constructed 


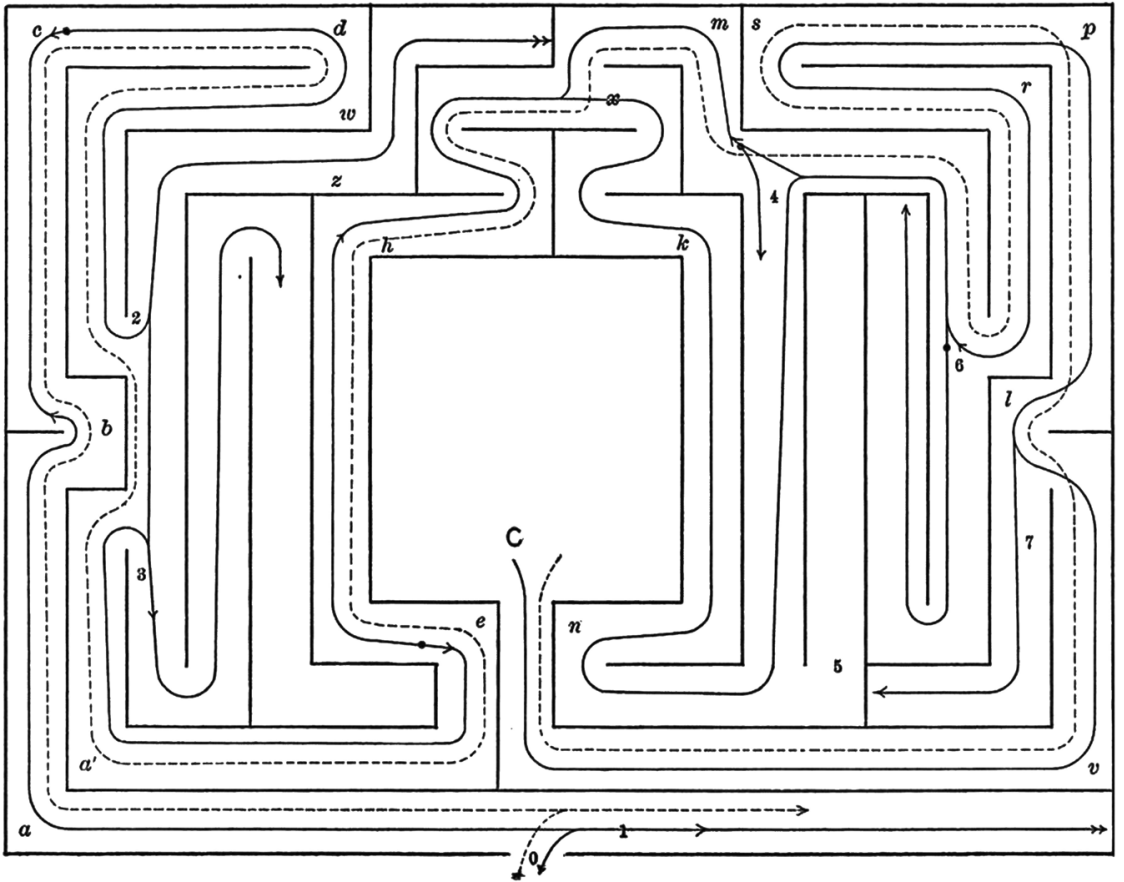

Figure 5. Small's Hampton court maze.

of wire mesh and placed on a sawdust-covered wooden floor. Three mazes were made. The other two mazes were identical to the first one except for the fact that they were made entirely - the bottom as well as the top and sides - of wire netting [27]. The food was placed inside the box, and two white rats were placed together at the entrance. Working independently, they explored backwards and forwards throughout the maze, pausing to dig in the sawdust or bite the wires. The first rat reached the food in 13 minutes. They were left in the maze all night, and when tested the next day, they covered the distance from entrance to food in 3 minutes. In subsequent trials the time required was further reduced and the errors (entering a blind alley or retracing the main path) decreased to one or two per trial. In an intermediate stage of learning, they would hesitate near the entrance and then "flash" through to the goal. They would enter a previously explored blind alley slowly and then run out quickly. When not very hungry, they would "play by the way, strolling nonchalantly into the blind alleys" [27] but then making a quick dash to the goal box. Even when their run from start to finish was error-free, it was not a stereotyped motor routine. This maze offered two alternative paths, both leading to the goal but one was shorter than the other; in time the rats came to take the shorter route almost exclusively. After the maze had been well learned, the experimenter opened up a short cut, which the rats quickly adopted.

Small's observations led him to the theory that the associative process consisted of the persistence of the feeling of hunger and the location of the food inside of the box, i.e., as a memory of getting the food inside the box [24]. In other words, the rats learned the place rather than a sequence of movements. He con- 
cluded that "The central fact in the process seems to be the recognition by the rats of particular parts of the maze" [27]. In addition, there was a difference between the rats, because of the quick learning of the "leading" rat.

While Small's interest was in studying learning, Kline's attention was at first attracted by the "food-box-finding" capacity of rats which, being gnawers, had to be studied "under the hunger impulse, free from fear, and, as far as possible, under natural conditions" [25]. In fact, in the conviction that the natural method and the experimental one "are necessary to a more abundant ingathering of facts" [28], he adopted an epistemological approach to the research on animals' learning that ranged from careful and continuous observations of naturally occurring behaviours to laboratory experimental observations involving mazes which, however, would inhibit the animals' ability to act freely. The idea for the second approach came from his 1897 research on chicks' "sickness for home", which involved reading Association in Animals, a chapter of Morgan's Introduction to Comparative Psychology, where the author explained the use of little boxes similar to traps to study the ways in which rats searched for food in out-of-the-way places, and observing an investigation conducted in 1897 in the Department of Biology at Clark by Colin C. Stewart, whose "methods, apparatus, and techniques were both interesting and instructive and made a decided impression" upon Kline. The importance lay inter alia in the use of rats and mice for the experiments, because "they are small, cheap, easily fed and cared for" [25]. Finally, Small's first Hampton maze, which he was able to observe in the hallway in front of the entrance to the laboratory machine shop of Clark University, gave him an idea for the construction of a similar device [25].

Kline's box was 8 inches long, 7 inches wide, 6 inches deep, with sides of wire, a glass top and a wooden bottom [28]. The box was raised above the level of the floor by two supporting strips 1 1/2 inches thick (Figure 6). Figure 6(a) shows the side view and Figure 6(b) the entrance and front view [25]. This experimental box was then put into the animals' home box, which also served as an observation box. It was 18 inches long, 14 inches wide and 14 inches deep; one side was made of wire, one end of glass and the rest of wood. The rats were placed in the home box several days before the experiments to become familiar with their surroundings [28]. After a series of 13 observations, Kline expressed his doubts about the possibility of establishing the associative chain in a very stable and clear form, since the rats "seldom begin digging at the proper place, sometimes will begin holes in several different places, and they will not dig at all until they have made several examinations of the box" [28]. Consequently, it could be said in pre-Piagetian terms, he established the "dividing lines between instinct, intelligence, and habit", because "it was instinct that prompted my chicks to perch, or my rats to scratch up the sawdust; it was intelligence gained through experience, that enabled the chicks to escape from the yard, and the rats to get food from the box; it was habit that made the chicks go in a particular roosting box, unsolicited, at the approach of night while they were wholly indifferent to another box and would escape from it if put in it" [28]. 


\section{MOUSE BOX NUMBER 1 .}
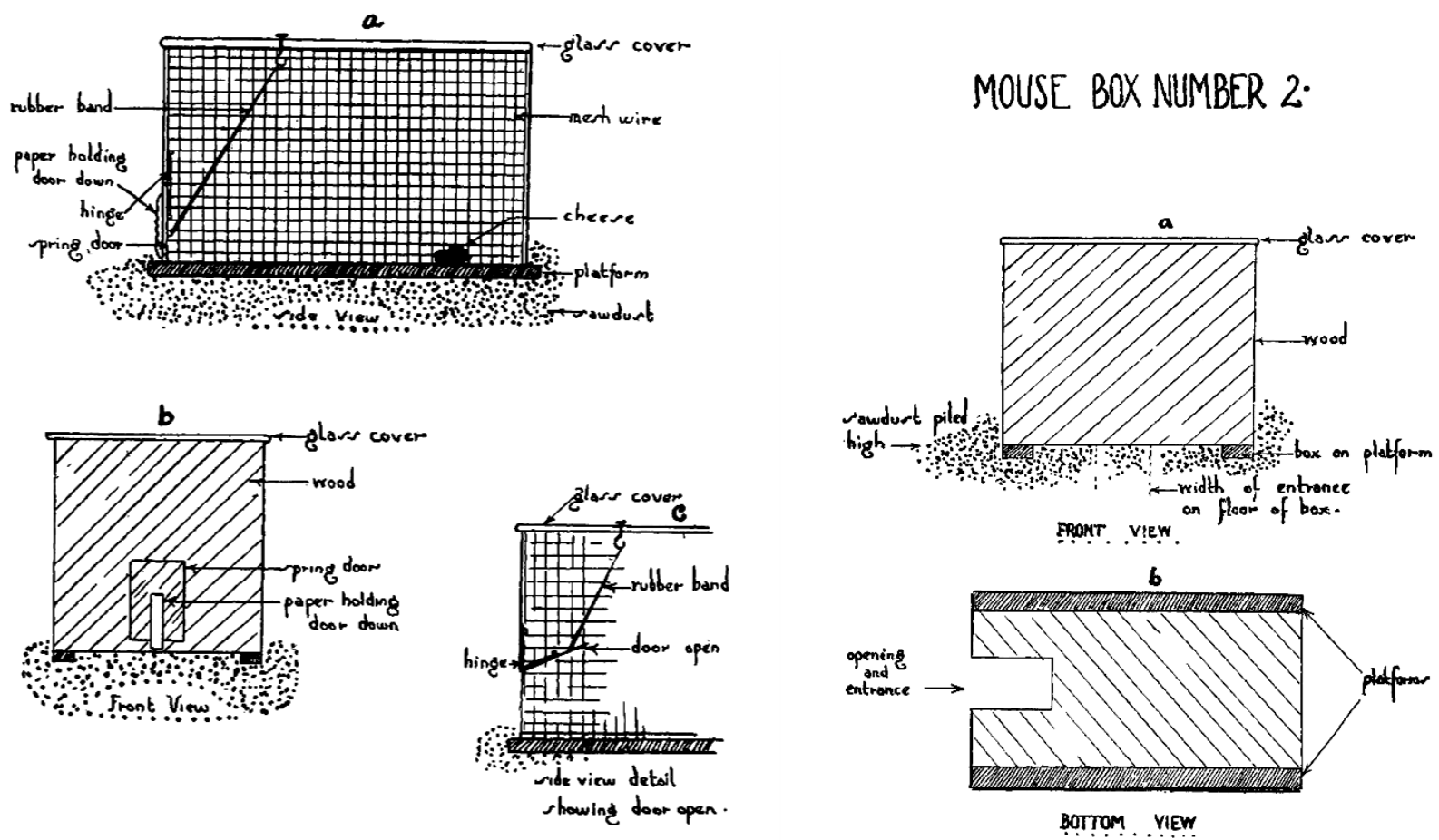

(a)

(b)

Figure 6. Smile's boxes.

\section{Kinesthesis in Maze Performance}

The fact that animals could quickly learn a complex maze opened up various theoretical problems. In trying to reach conclusive solutions, psychologists varied the maze pattern, standardized the experimental procedure and quantified the scoring of the animal's performance. Among them was John B. Watson, whose research was focused on the identification of sensory cues [29]. The impetus was given by his 1903 doctoral dissertation and first published research Animal Education: An Experimental Study of the Psychological Development of the White Rat. In Correlated with the Growth of Its Nervous System, he sought to correlate the growth of the central nervous system and the development of learning ability or, in other words, to clarify: "1) How far is it possible [...] to give a systematic account of the gradual unfolding of the associative processes in the rat? 2) Is it possible [...] to find out whether or not medullated nerve fibers in the cortex of the rat are a conditio sine qua non of the rat's forming and retaining definite associations? 3) Is there any demonstrable connection between the increasing complexity of the psychical life, as manifested in the ability of the rat to form increasingly complex associations, and the number of medullated fibers in the cortex, together with their extension toward its surface?" [30]. 
The starting point of his reflections was the observation that researchers had not demonstrated that rats could form associations except in relation to the sense of smell [30]. In contrast to the prevailing beliefs of the time, Watson was convinced that the animals were "capable of forming and retaining associations comparable [...] to associations formed by dogs, cats, and monkeys" [30], as Small had in part demonstrated. Moreover, following Morgan's suggestions, he decided to adopt a descriptive, inductive method that would allow him to look at the formation of associations, rather than taking them already formed, i.e., learning had to be considered as "a gradual selection of certain acts and movements in the given situation by reason of the satisfaction they bring" [30]. That is why he preferred to use the term "pattern of behaviour" or "habit" instead of "association". Following Thorndike and Small's method and procedure, the rats were left hungry, and food was then placed inside the problem box to ascertain whether animals that had already learned the maze could still traverse it without error, and whether previously untrained animals could learn the maze as quickly as the trained ones.

As for their psychical development, which was carefully observed by controlling both the laboratory conditions (eliminating, for example, loud noise) and the conditions of his rats before and during the trials, Watson found that 23-day-old rats were able to solve any simpler problem like the adult rats, whereas the latter could also quickly solve problems requiring more complex discernment, probably thanks to their greater exposure to a variety of problems. Younger rats showed "superabundant physical activity and lack of muscular control" [30] with movements that served no purpose in solving the problems, whereas adult rats abandoned superfluous activity quickly.

To answer the second and third question, then, i.e., the correlation between the growth of the central nervous system and the activities of the white rat and the role of the medullated fibers in the cortex, Watson dissected the brains of 23 rats aged between 2 hours and 42 days and one rat recorded as an "adult" [30]. His conclusion was that when the rats reached their full psychical development at about 23 days of age, the medullation process was still far from complete. In any case, "1) Medullated fibers in the cortex of the rat are not a condition sine qua non of the rat's forming and retaining definite associations; 2) the complexity of the psychical life increases much more rapidly than does the medullation process in the cortex, psychical maturity being reached when approximately only one-fifth of the total number of fibers in the cortex are medullated" [30].

During the 1904 Congress of Art and Sciences in St. Louis, Watson explained his next project, which aimed to determine the "relative importance of the several sensations of any given animal in its adjustment to its environment" [31], thus adopting the opposite direction to contemporary research into the function of the sense organs, which involved performing preparatory surgery on untrained animals and then studying the immediate and local effects of the operation, with scarce "attention to the effect of the operations upon the instinctively 
and habitually organized reactions of the animal as a whole" [31].

To identify the specific sensory cues used to learn a maze, Watson followed the established scientific research procedures of the time. For his apparatus he used the same maze in all experiments (Figure 7). The bottom of the maze and the sides of the galleries were made of wood $7 / 8$ of an inch thick. The top of the maze was of $1 / 4$-inch-mesh wire netting. The plan of the maze was a duplicate of the one used by Small, except that the dimensions of the ground plan were 5 by 7 feet. Obviously, as the dimensions of the galleries were the same as in Small's maze, the central food-box was smaller than the other food-box. The distance (represented by the broken line) from the entrance of the maze to the central food-box was 40 feet [31].

In 1904 in Chicago Watson had met Harvey Carr, one of Angell's students, and he decided to carry out with him the experiments with rats. The research began the following year. To study the role of vision, Carr trained rats in a lighted maze; they then ran in a darkened maze and subsequently in the light once more. No differences were found in the rats' performances. Carr placed visual and tactual stimuli at selected points in the maze to ascertain their influence on performance: the rats' behaviour was the same [32]. In the light of these results, Watson decided to proceed by depriving each rat of one sense at a time by applying the surgical procedures and techniques he had learned in the summer of 1905 under William Howell of John Hopkins. In 1906 he began to operate on six-month-old rats that had previously learned the maze. He made one group blind by removing their eyeballs and one group deaf by removing their middle ear, and he removed the olfactory bulb from another group to ensure they could not smell [31].

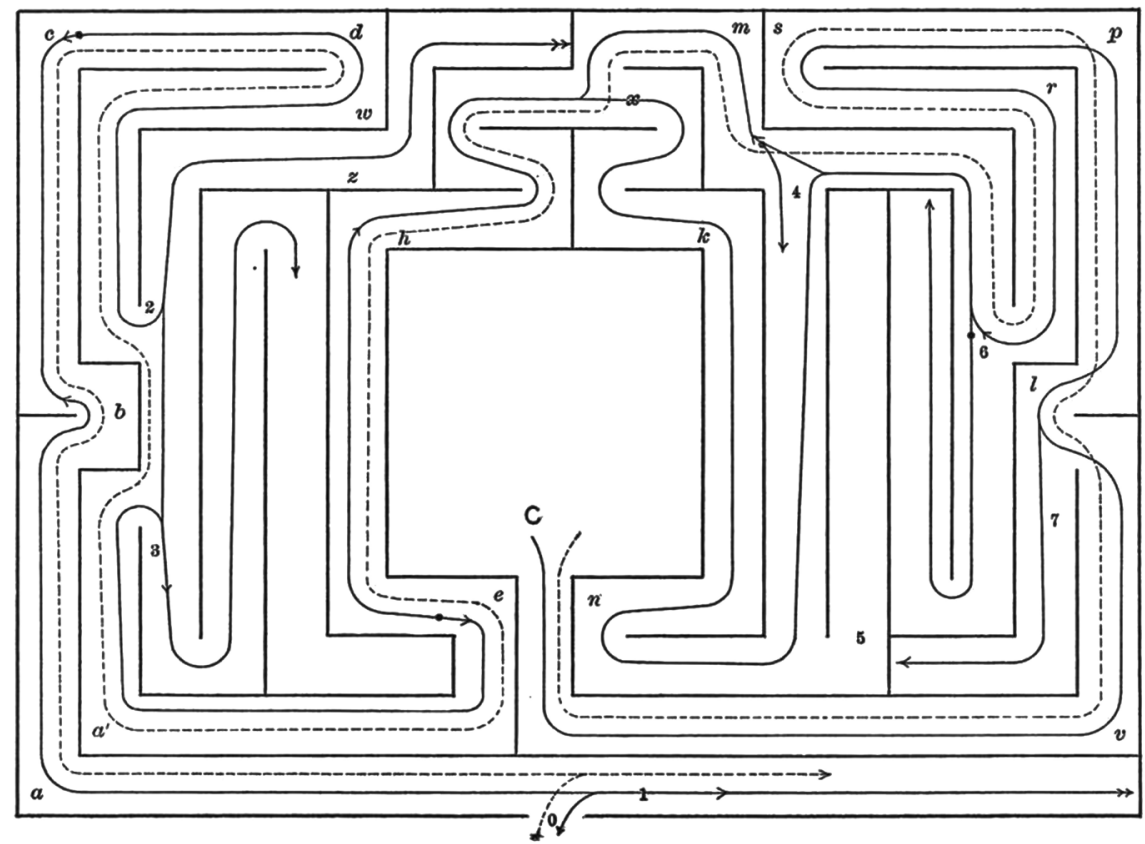

Figure 7. Watson's maze. 


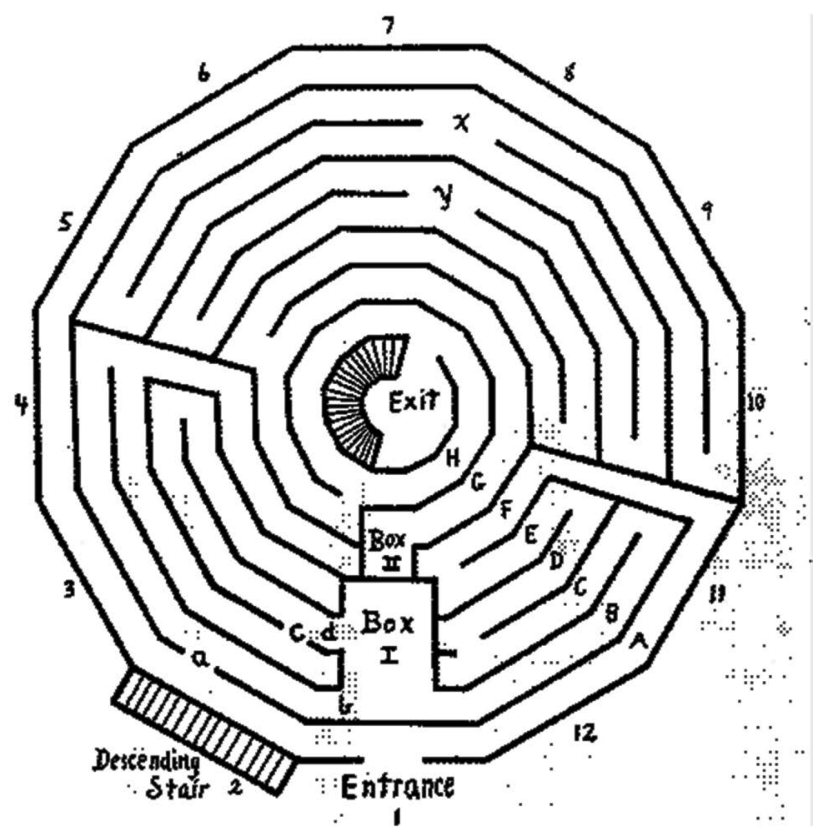

Figure 8. Perrin's circular maze.

After 18 months of investigation, the two researchers concluded that well-trained rats, even though deprived of their major sensory abilities, after full recovery from each operation were able to traverse the maze very fast and "with confidence", and this with different views of the device's orientation (compass sense), different air currents, and different path length. In one experiment, for example, after training, the rats were released into a path reduced in length by half; food was placed in front of the new end. The animals ignored the food and ran nose-first into the end of the maze, making a "kerplunk" sound (hence the nickname: the "kerplunk experiment"). If the path was longer, the rats ran until they reached their usual distance, i.e., the distance at which the food was normally located. After that, they paused to sniff the area, even though they had not reached the end of the path, often ignoring food that was located further along.

Armed with these results, Watson and Carr performed the same operations on a new group of rats, and found that these rats too learned the maze as well as the rats with full sensory apparatus. Hypothesizing that the rats were making use of their whiskers, Watson eliminated their whiskers and destroyed their sense of taste. This made no difference whatsoever to the results. Watson and Carr finally inferred that the essential cues in maze learning and running were provided by a series of associated movements, or kinaesthesia, instead of stimuli from the outside world. Other internal senses, such as the organic, might play some part; but the external senses were not essential in guiding the rats, as Watson had already shown [31].

This conclusion was not entirely accepted. In a review, Margaret Floy Washburn [33] [34] took issue both with the over-emphasis on the role of kinesthetic sensations and muscular movements in maze performances and with the comparison between the behaviours of rats and human beings, which Carr and 

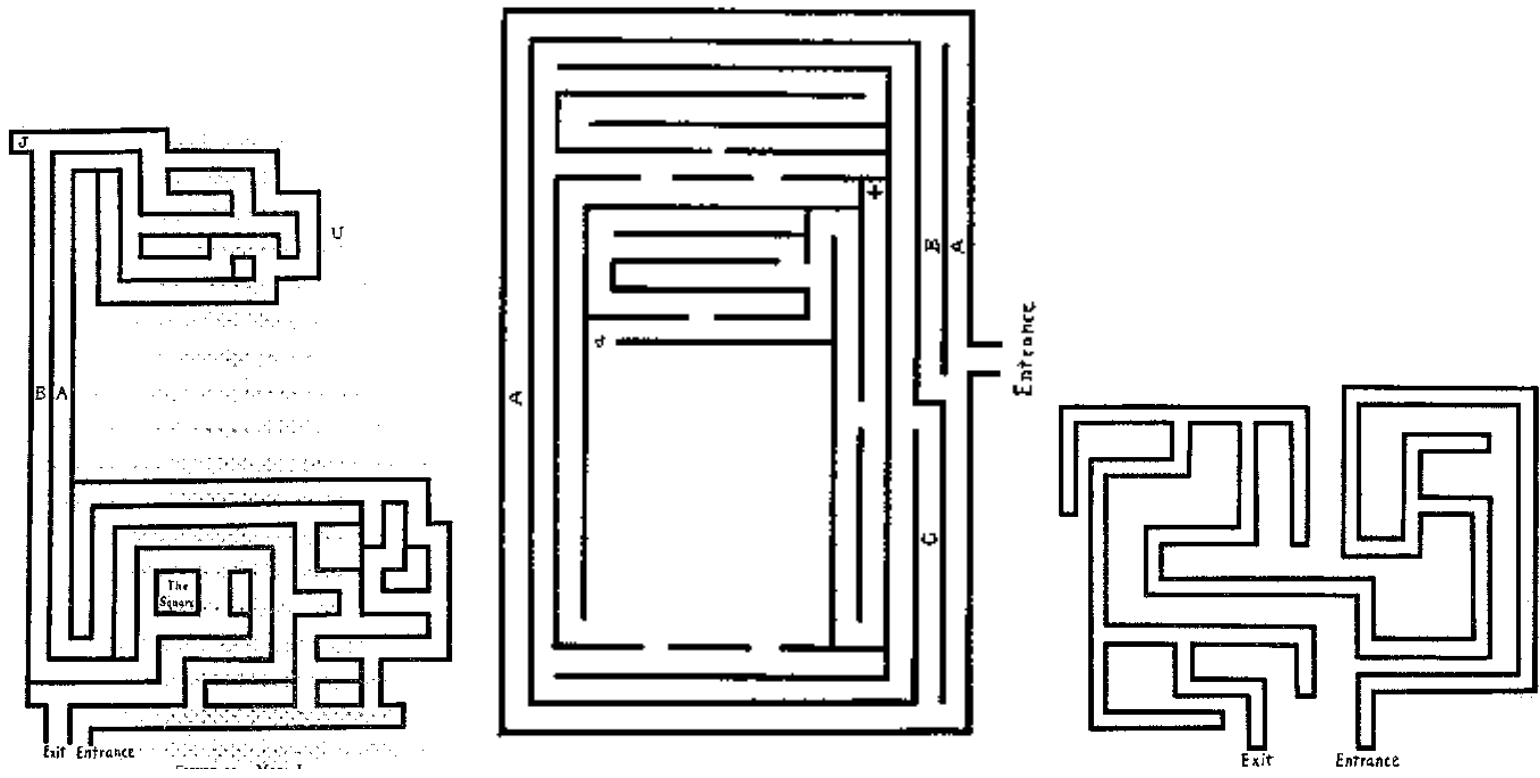

Figure 9. Perrin's Hampton Court mazes to be covered by humans with a pencil or a stylus.

Watson made in the last part of their work [32]. Although admitting the impossibility that animal consciousness could be measured directly, she stated her intention to explore animal mental phenomena, such as learning and attention, which were-according to her-similar to those of humans. The criticism levelled by Washburn, the first woman to receive a $\mathrm{PhD}$ in psychology, in 1894, was partly due to her different approach to the study of animal learning. In the same year as her review of Carr and Watson's work [32], she published The Animal Mind: A Text-Book of Comparative Psychology [33] [34], which was reprinted in 1917, 1926, and 1936. The main thesis was that, by taking care to avoid the temptation of anthropomorphism, which could interfere as a source of error, the workings of animals' minds could be inferred from their behaviour, which was an analogon of human conscious experience. As she stated, "Our acquaintance with the mind of animals rests upon the same basis as our acquaintance with the mind of our fellow man; both are derived by inference from observed behavior. [...] We know not where consciousness begins in the animal world. We know where it surely exists - in ourselves; we know where it exists beyond a reasonable doubt - in those animals of structure resembling ours which readily adapt themselves to the lessons of experience. Beyond this point, for all we know, it may exist in simpler and simpler forms until we reach the very lowest of living beings" [33] [34]. Consequently, her investigations were not limited to rats or cats and dogs and to their muscular movements, but they concerned the ability to use various sensory modalities of "not fewer than 100 species, including ants, bees, caterpillars, cats, chicken, chubs, clams, cockroaches, cows, crabs, crayfish", etc., as well as the amoeba [35].

The devices Washburn used took different forms, ranging from simple mazes to complex ones as well as T-mazes, etc., and they provide a clear illustration of 
the rapid proliferation of maze designs. In 1927, proposing a standardized maze, Warner and Warden noted the use of more than 100 different maze patterns [36]. It was an era in which mazes of all kinds-open or elevated [37], walled and unwalled [38] [39], U, T, Y and linear-were constructed for animals, blindfolded human adults and human children [40]. For example, in 1914 Perrin made an approximately circular maze for blindfolded subjects in an amusement park (Figure 8); he also used a small model of the Hampton Court maze, the paths through which were traced by the subject with a pencil or a stylus (Figure 9) [41], thus paving the way for procedures such as the high-relief finger mazes, the Porteus Maze Test [42] [43], etc., which drew psychologists' attention to motivation or previous memory. The history of the maze, however, was still not over: in 1984, in a period dominated by interest in neurosciences, Richard G. Morris created a water maze to measure spatial ability [44]. In short the maze has always been "present" in the history of psychology right from the birth of the discipline.

\section{Conflicts of Interest}

The author declares no conflicts of interest regarding the publication of this paper.

\section{References}

[1] Kerényi, K. (1950) Labyrinth-Studien. Rhein Verlag, Zürich.

[2] Darwin, C. (1881) The Formation of Vegetable Mould, through the Action of Worms, with Observations on Their Habits. University of Chicago Press, Chicago, IL. https://doi.org/10.5962/bhl.title.107559

[3] Romanes, G.J. (1882) Animal Intelligence. D. Appleton, New York.

[4] Spalding, D.A. (1872) On Instinct. Nature, 6, 485-486. https://doi.org/10.1038/006485a0

[5] Spalding, D.A. (1873) Instinct. With Original Observations on Young Animals. Macmillan's Magazine, 27, 282-293.

[6] Boakes, R. (1984) From Darwin to Behaviourism: Psychology and the Minds of Animals. Cambridge University Press, New York.

[7] Lloyd, M.C. (1894) An Introduction to Comparative Psychology. Walter Scott, London, 304.

[8] Goodwin, C.J. (2003) Psychology's Experimental Foundations. In: Davis, S.F., Ed., Handbook of Research Methods in Experimental Psychology, Blackwell, Malden, 3-23. https://doi.org/10.1002/9780470756973.ch1

[9] Goodwin, C.J. (1991) Maze Learning as Method: Origins and Early Development. American Psychological Association, San Francisco.

[10] Woodworth, R.S. and Schlosberg, H. (1938) Experimental Psychology. Holt, New York, 614-654.

[11] Olton, D.S. (1979) Mazes, Maps, and Memory. American Psychologist, 34, 583-596. https://doi.org/10.1037/0003-066X.34.7.583

[12] Thorndike, E.L. (1898) Animal Intelligence: An Experimental Study of the Associative Processes in Animals. Psychological Review, Monograph Supplements, 2, 
4-160. https://doi.org/10.1037/10780-000

[13] Bain, A. (1855) The Senses and the Intellect. Parker, London. https://doi.org/10.1037/12115-000

[14] Bain, A. (1870) Mental Science, a Compendium of Psychology, and the History of Philosophy. Appleton, New York.

[15] Stam, H.J. and Kalmanovitch, T. (1998) E. L. Thorndike and the Origins of Animal Psychology. On the Nature of the Animal in Psychology. American Psychologist, 3, 1135-1144. https://doi.org/10.1037/0003-066X.53.10.1135

[16] Romanes, G.J. (1893) Mental Evolution in Animals. Degan Paul, Trench, Trubner \& Co., London.

[17] Thorndike, E.L. (1899) The Instinctive Reaction of Young Chicks. Psychological Review, 6, 282-291. https://doi.org/10.1037/h0073000

[18] Thorndike, E.L. (1911) Animal Intelligence: Experimental Studies. MacMillan, New York. https://doi.org/10.5962/bhl.title.55072

[19] Thorndike, E.L. (1901) The Mental Life of Monkeys. Psychological Review. Monograph Supplements, 3, i-57. https://doi.org/10.1037/h0092994

[20] Vincent, S.B. (1912) The Function of the Vibrissae in the Behaviour of the White Rat. Behavior Monographs, 1, 1-82.

[21] Hobhouse, L.T. (1901) Mind in Evolution. MacMillan, New York, 141-151. https://doi.org/10.1037/10914-000

[22] Adams, D.K. (1929) Experimental Studies of Adaptive Behavior in Cats. Comparative Psychological Monographs, 6, 1-168.

[23] Bitterman, M.E. (1969) Thorndike and the Problem of Animal Intelligence. American Psychologist, 24, 444-453. https://doi.org/10.1037/h0027942

[24] Small, W.S (1900) An Experimental Study of the Mental Processes of the Rat. American Journal of Psychology, 11, 133-164. https://doi.org/10.2307/1412267

[25] Miles, W.R. (1930) On the History of Research with Rats and Mazes: A Collection of Notes. Journal of General Psychology, 3, 324-327. https://doi.org/10.1080/00221309.1930.9918210

[26] Small, W.S. (1898) Suggestions toward a Laboratory Course. Journal of Comparative Psychology, 10, 399-430. https://doi.org/10.2307/1412142

[27] Small, W.S. (1901) An Experimental Study of the Mental Processes of the Rat. II. American Journal of Psychology, 12, 206-239. https://doi.org/10.2307/1412534

[28] Kline, L.W. (1899) Methods in Animal Psychology. American Journal of Psycholo$g y$, 10, 256-279. https://doi.org/10.2307/1412481

[29] Todd, J.T. and Morris, E.K. (1986) The Early Research of John B. Watson: Before the Behavioral Revolution. The Behavior Analyst, 9, 71-88.

https://doi.org/10.1007/BF03391931

[30] Watson, J.B. (1903) Animal Education: An Experimental Study of the Psychological Development of the White Rat. Correlated with the Growth of Its Nervous System. University of Chicago Press, Chicago.

[31] Watson, J.B. (1907) Kinesthetic and Organic Sensations: Their Role in the Reactions of the White Rat to the Maze. Psychological Review. Monograph Supplements, 8, i-101. https://doi.org/10.1037/h0093040

[32] Carr, H. and Watson, J.B. (1908) Orientation in the White Rat. Journal of Comparative Neurology and Psychology, 18, 27-44.

https://doi.org/10.1002/cne.920180103 
[33] Washburn, M.F. (1908) The Animal Mind: A Text-Book of Comparative Psychology. Mcmillian Company, New York. https://doi.org/10.5962/bhl.title.31648

[34] Washburn, M.F. (1908) Review of Orientation in the White Rat. Journal of Philosophy, Psychology and Scientific Methods, 5, 275-277. https://doi.org/10.2307/2011775

[35] Washburn, D.A. (2010) The Animal Mind at 100. Psychological Review, 60, 369-376. https://doi.org/10.1007/BF03395714

[36] Warner, C.H. and Warden, C.J. (1927) The Development of a Standardized Animal Maze. Archives of Psychology, 15 (Whole No. 92).

[37] Miles, W.R. (1930) The Comparative Learning of Rats on Elevated and Alley Mazes of the Same Pattern. Journal of Comparative Psychology, 10, 237-261. https://doi.org/10.1037/h0073783

[38] Lindley, S.B. (1939) The Maze-Learning Ability of Anomic and Blind Anomic Rats. Journal of Genetic Psychology, 37, 245-267. https://doi.org/10.1080/08856559.1930.10532237

[39] Snygg, D. (1935) Maze in Which Rats Take the Longer Path to Food. Journal of Psychology, 1, 153-166. https://doi.org/10.1080/00223980.1935.9917250

[40] Hicks, V.C. and Carr, H. (1912) Human Reactions in a Maze. Journal of Animal Behavior, 2, 98-125. https://doi.org/10.1037/h0073751

[41] Perrin, F.A.C. (1914) An Experimental and Introspective Study of the Human Learning Process in the Maze. Psychological Review, Monograph Supplements, Whole No. 70. https://doi.org/10.1037/h0093081

[42] Porteus, S.D. (1933) The Maze Test and Mental Differences. Vineland. Smith Printing and Publishing House, Vineland, 212 p. https://doi.org/10.1037/11351-000

[43] Porteus, S.D. (1950) The Porteus Maze Test and Intelligence. Pacific Books, Palo Alto, Calif.

[44] Morris, R.G.M. (1984) Developments of a Water Maze Procedure for Studying Spatial Learning in the Rat. Journal of Neuroscience Methods, 11, 47-60.

https://doi.org/10.1016/0165-0270(84)90007-4 